\title{
Comunicação
}

[Communication $]$

\section{Prevalência e perfil de resistência a antimicrobianos de sorovares de Salmonella isolados de lingüiças suínas tipo frescal em Lages, SC}

\author{
[Prevalence and profile of resistance to antimicrobials of Salmonella serovars isolated \\ from raw pork sausage in Lages, $S C]$ \\ D.A. Spricigo, S.R. Matsumoto, M.L. Espíndola, E.K. Vaz, S.M. Ferraz \\ Centro de Ciências Agroveterinárias - UDESC \\ Av. Luiz de Camões, 2090 \\ 88520-050 - Lages, SC
}

A Salmonella é reconhecida como uma das principais causas mundiais de toxinfecção alimentar. Geralmente, os surtos em humanos estão associados a produtos de origem animal (Rostagno, 2002). Em países desenvolvidos, esses produtos correspondem a $80-90 \%$ dos casos, sendo a carne suína responsável por 530\% deles (Berends et al., 1998).

A crescente demanda de derivados suínos tipo frescal pode significar aumento de sua participação nos surtos de salmonelose em humanos (Castagna et al., 2004b). Dentre estes, a lingüiça apresenta o maior risco, pois pode ocorrer contaminação e proliferação dos microrganismos durante o preparo, manufatura e estoque do produto (Giovannini et al., 2004). Além disso, trabalhos recentes comprovam a relação entre a presença de Salmonella sp. nos linfonodos submandibulares e tonsilas, que ficam agregados à massa de embutidos, e no conteúdo intestinal de suínos ao abate, com o isolamento de microrganismos no produto final (Castagna et al., 2004b). Outro fator comprovado é a alta prevalência de Salmonella sp. em suínos pré e pós abate (Bessa et al., 2006; Castagna et al., 2004a; Silva et al., 2006 ).

No Brasil, somente os estados do Rio de Janeiro, Rio Grande do Sul e Mato Grosso apresentam algum tipo de análise de prevalência de Salmonella sp. em produtos cárneos de origem suína (Chaves et al., 2000; Loguercio et al., 2002). No entanto, apesar da importância de

Recebido em 18 de setembro de 2007

Aceito em 26 de março de 2008

E-mail: sandra@cav.udesc.br
Santa Catarina (SC) na produção suinícola, não há estudos sobre o assunto no estado. Os objetivos deste trabalho foram avaliar a prevalência de sorovares de Salmonella em lingüiças tipo frescal de matéria-prima suína comercializadas no município de Lages/SC e identificar o perfil de resistência desses sorovares aos antimicrobianos utilizados na medicina humana e veterinária.

Foram coletadas, aleatoriamente, 125 amostras de lingüiça tipo frescal de matéria-prima suína, de 12 diferentes marcas disponíveis (A-M) no comércio de Lages/SC, no período de março a agosto de 2005. O número de amostras por marca não foi homogêneo devido à maior disponibilidade de algumas delas. No laboratório, as amostras foram mantidas refrigeradas $\left(4^{\circ} \mathrm{C}\right)$ até o momento do processamento, e esse procedimento não ultrapassou seis horas.

A metodologia utilizada para o isolamento de Salmonella sp. seguiu o descrito por Michael et al. (2000). As colônias suspeitas foram identificadas por meio de suas características morfológicas e bioquímicas e, após, foram confirmadas como Salmonella sp. por meio de provas de aglutinação em soro polivalente ${ }^{1}$. Os isolados foram encaminhados ao Instituto Oswaldo Cruz para a sorotipificação. Todos os sorovares foram testados quanto a resistência aos antimicrobianos pelo método de difusão em ágar Mueller-Hinton. Foram utilizados discos ${ }^{2}$ dos seguintes antimicrobianos: ácido nalidíxico (An-

${ }^{1}$ Soro Salmonella polivalente, PROBAC - São Paulo, Brasil.

${ }^{2}$ Sensidisc, DME - Araçatuba, Brasil. 
20/10ug), amicacina (Am-30ug), amoxicilina/ácido clavulânico (Ac-20-10ug), ampicilina (Ap-10ug), cefaclor (Cf-30ug), ciprofloxacina (Ci-5ug), cloranfenicol (Cl-30ug), cotrimoxazol (St-5ug), estreptomicina (Es-10ug), gentamicina (Ge-10ug), neomicina (Ne-30ug), sulfonamida (Sl-300ug), tetraciclina (Te-30ug) e tobramicina (Tb-10ug).

Observou-se prevalência de Salmonella sp. de $12,8 \%(16 / 125)$ das amostras. Pelo menos uma das amostras foi positiva em sete das 12 marcas analisadas, sendo de $18,5 \%$ a prevalência na marca $\mathrm{B}$, uma das mais encontradas no comércio. A legislação brasileira determina a ausência desse patógeno em $25 \mathrm{~g}$ de amostras analisadas (Portaria..., 1997).

No Brasil, existem poucos estudos sobre a presença Salmonella sp. em produtos frescais suínos. No Rio de Janeiro e no Rio Grande do Sul, foram encontradas prevalências semelhantes, 10,0 e $11,8 \%$, respectivamente (Chaves et al., 2000; Loguercio et al., 2002), e no Mato Grosso, 26\% (Reis et al., 1995). Neste último trabalho, foram testados produtos cárneos suínos de uma forma geral, enquanto nos outros foram apenas lingüiças suínas. Estudo recente, realizado no Rio Grande do Sul, verificou 93,9\% de amostras de massa para lingüiça contaminadas por Salmonella sp. (Castagna et al., 2004b).

Apesar da grande diversidade de sorovares encontrada neste estudo, na marca $\mathrm{E}$ todos os isolados foram do sorovar Typhimurium. Escartín et al. (1995) verificaram uma diversidade igualmente grande de Salmonella sp. isoladas de carne suína crua. Isso pode ser atribuído às diferentes origens de contaminação, relacionadas tanto com os sorovares presentes nos lotes, quanto com possíveis contaminações cruzadas durante o processamento (Castagna et al., 2004b).

Nos estudos de Castagna et al. (2004b) e Giovannini et al. (2004), os sorovares mais encontrados foram Typhimurium (43,7\% - 7/16) e Derby $(18,8 \%$ - 3/16). Apesar de todos os sorovares de Salmonella sp. serem considerados potencialmente patogênicos para humanos, a maioria dos surtos têm sido relacionados a apenas alguns, sendo Enteritidis e Typhimurium os mais freqüentes (Schlosser et al., 2000). No
Brasil, os sorovares Typhimurium, Enteritidis, Infantis e Agona foram identificados em casos de infecção alimentar em humanos. Mais recentemente, sorovar Enteritidis foi o mais encontrado (Esper et al., 1998; Jakabi et al., 1999).

As maiores resistências ocorreram frente às: sulfonamida e tetraciclina (13/16 - 81,25\%), ampicilina (8/16 - 50,00\%), cloranfenicol (5/16 $31,25 \%)$, cotrimoxazol (4/16 - 25,00\%), amoxacilina/ácido clavulânico (3/16 - 18,75\%), ácido nalidíxico, cefaclor, ciprofloxacina, neomicina e tobramicina $(2 / 16-12,50 \%)$, e nenhum sorovar apresentou resistência à amicacina, estreptomicina e gentamicina. Mais ainda, 12 amostras apresentaram resistência intermediária à neomicina. Dos sorovares isolados, 50\% (8/16) foram resistentes a, pelo menos, quatro antimicrobianos, e, como tal, foram considerados multirresistentes, destacando-se o sorovar S. enterica subsp enterica 0:3,10:h (8/14). Resultados semelhantes foram encontrados por Cruchaga et al. (2001), com o sorovar Typhimurium, sendo o multirresistente mais predominante. Nielsen et al. (1999) apontaram o sorovar Typhimurium como aquele com maior tendência a adquirir perfil de multirresistência, e todas essas cepas multirresistentes podem caracterizar um risco à saúde do consumidor. Surtos causados por elas podem representar uma barreira para o sucesso do tratamento, aumentando o custo do tratamento e a mortalidade na população de risco. A antibioticoterapia não é necessária em casos usuais de salmonelose, entretanto o é nas infecções generalizadas e em pacientes de risco (Parry, 2003).

Vários autores têm associado o aumento da resistência bacteriana a antimicrobianos com a administração excessiva a animais criados para a produção de alimentos (Cruchaga et al., 2001; Schwarz et al., 2001). Outros autores (FedorkaCray et al., 1999; Isaacson et al., 2001) observaram, ainda, que os maiores índices de resistência ocorriam contra antimicrobianos disponíveis há mais tempo no mercado e que eram comumente utilizados na terapêutica. Dessa forma, o alto número de amostras resistentes à tetraciclina, encontrado no presente estudo, poderia ser explicado pelo seu uso freqüente há vários anos. 
Além de todas as amostras da marca E serem do mesmo sorovar, apresentaram o mesmo perfil de resistência (SITe). Isto pode indicar que sejam da mesma linhagem, porém, para melhor discriminação entre os isolados, deveriam ser realizadas as técnicas de fagotipificação e eletroforese em campo pulsado (Bessa, 2006).

Como o brasileiro tem o hábito de tratar pelo calor a lingüiça frescal antes do consumo, o risco de surtos está relacionado à contaminação cruzada de alimentos que possam ser consumidos crus (Escartín et al., 2000; Gorman et al., 2002). É preciso considerar também que a estocagem inadequada permite que o microrganismo se multiplique até atingir a dose infectante (Sojka e Gitter, 1961)
A maioria das marcas de lingüiça tipo frescal suína analisadas encontra-se fora dos padrões da legislação brasileira, representando um risco à saúde pública, pois o produto é de grande aceitação pelos consumidores. Além disso, o alto número de isolados resistentes indica que os produtores e médicos veterinários devem se preocupar em monitorar o uso de antimicrobianos na granja, para controlar o risco de seleção e transmissão de linhagens resistentes por meio da cadeia alimentar.

Palavras-chave: suíno, lingüiça, Salmonella sp., antimicrobiano, multirresistência

\begin{abstract}
The prevalence and profile of resistance to antimicrobials of Salmonella serovars isolated from raw pork sausage were studied in Lages county, Santa Catarina, Brazil. A total of 125 samples of 12 trademarks were collected in different commercial establishments. Salmonella sp. was present in 12.8\% (16/125) of the samples and Typhimurium serovar was the most prevalent. Fourteen different antimicrobials were tested and most of the samples showed resistance to sulfonamide and tetracycline (81.2\%). Eight positive samples (50\%) were resistant at least to four antimicrobials, being considered as multi-resistant Salmonella. Seven (58.3\%) trademarks were disagreement with the Brazilian law, representing a risk to the public health. The high level of resistance to the antimicrobials should produce a concern by the pig industry and veterinarians in order to prevent the transmission of resistant strains through the food chain.
\end{abstract}

Keywords: sausage, swine, Salmonella sp., antimicrobials, multi-resistant

\section{AGRADECIMENTOS}

À Dra. Eliane Falavina dos Reis, Departamento de Bacteriologia, Instituto Oswaldo Cruz, pela sorotipificação das amostras. Ao Professor Sérgio Dallagnol, Laboratório de Patologia Aviária-CAV/UDESC, pelo auxílio na realização deste trabalho.

\section{REFERÊNCIAS BIBLIOGRÁFICAS}

BESSA, M.C. Caracterização fenotipica e genotípica de amostras de Salmonella enterica sorovar Typhimurium isoladas de suínos no Rio Grande do Sul. 2006. 145f. Tese (Doutorado) - Universidade Federal do Rio Grande do Sul, Porto Alegre.

BERENDS, B.R.; VAN KNAPEN, F.; MOSSEL, D.A.A. et al. Impact on human health of Salmonella spp. on pork in The Netherlands and the anticipated effects of some currently proposed control strategies. Int. J. Food Microbiol., v.44, p.219-229, 1998.

CASTAGNA, S.M.F.; SCHWARZ, P.; CANAL, C.W. et al. Presença de Salmonella sp. no trato intestinal e em tonsilas/linfonodos submandibulares de suínos ao abate. Arq. Bras. Med. Vet. Zootec., v.56, p.300-306, $2004 \mathrm{a}$.

CASTAGNA, S.M.F.; SCHWARZ, P.; CANAL, C.W. et al. Prevalência de suínos portadores de Salmonella sp. ao abate e contaminação de embutidos tipo frescal. Acta Sci. Vet., v.32, p.141-147, 2004b.

CHAVES, G.M.C.; GONÇALVES, P.M.R.; FRANCO, R.M. et al. Avaliação bacteriológica de lingüiça frescal suína comercializada no município do Rio de Janeiro, RJ. Hig. Alim., v.14, p.48-52, 2000.

CRUCHAGA, S.; ECHEITA, A.; ALADUEÑA, A. et al. Antimicrobial resistance in Salmonellae from humans, food and animals in Spain in 1998. J. Antim. Chemisth., v.47, p.315-321, 2001.

ESCARTÍN, E.F.; LOZANO, J.S.; GARCÍA, O.R. 
Quantitative survival of native Salmonella serovars during storage of frozen raw pork. Int. J. Food. Microbiol., v.54, p.19-25, 2000

ESCARTÍN, E.F.; LOZANO, J.S.; GARCÍA, O.R. et al. Incidence and level of Salmonella serovars in raw pork obtained from Mexican butcher shops. Food Microbiol., v.12, p.435-439, 1995

ESPER, M.R.N.R.; FREITAS, A.M.; FERNANDES, S.A. et al. Salmonella: Sorotipos identificados das cepas isoladas de pacientes hospitalizados e não hospitalizados, na região de Presidente Prudente, SP, no período de 1978-1997. Rev. Inst. Adolfo Lutz, v.57, p.45-50, 1998.

FEDORKA-CRAY, P.J.; BAHNSON, P.B.; LADELY, S.R. Antimicrobial resistance patterns of Salmonella isolates collected from slaughter age pigs. In: INTERNATIONAL SYMPOSIUM ON THE EPIDEMIOLOGY AND CONTROL OF SALMONELLA IN PORK, 3., 1999, Washington. Proceedings...Washington, 1999. p.245-247.

GIOVANNINI, A.; PRENCIPE, V.; CONTE, A. et al. Quantative risk assessment of Salmonella spp. infection for the consumer of pork products in an italian region. Food Control, v.15, p.139-144, 2004.

GORMAN, R.; BLOOMFIELD, S.; ADLEY, C.C. A study of cross-contamination of food-borne pathogens in the domestic kitchen in the Republic of Ireland. Int. J. Food Microbiol., v.76, p.143-150, 2002

ISAACSON, R.E.; QIAO, B.; BARBER, D. A. et al. Antibiotic resistance patterns and genotypes of Salmonellae within swine production systems and the relationship to on farm use of antibiotics. In: INTERNATIONAL SYMPOSIUM ON THE EPIDEMIOLOGY AND CONTROL OF SALMONELLA IN PORK, 4., 2001, Leipzig. Proceedings...Leipzig, 2001. p.396-398.

JAKABI, M.; BUZZO, A.A.; RISTORI, C.A. et al. Observações laboratoriais sobre surtos alimentares de Salmonella sp., ocorridos na grande São Paulo, no período de 1994 a 1997. Rev. Inst. Adolfo Lutz, v.58, p.47-51, 1999.

LOGUERCIO, A.P.; ALEIXO, J.A.G.; VARGAS, A.C. et al. ELISA indireto na detecção de Salmonella spp. em lingüiça suína. Cienc. Rural, v.32, p.10571062,2002

MICHAEL, G. B. Comparação de diferentes etapas de enriquecimento seletivo no isolamento de Salmonella sp. a partir de fezes de suinos de terminação. 2000. 114 f. Dissertação (Mestrado) Universidade Federal do Rio Grande do Sul, Porto Alegre.

NIELSEN, B.; MOGELMOSE, V.; SORENSEN, L.L. et al. Tracing back multi-resistant Salmonella Typhimurium DT104 from pork at the slaughterhouse to a specific swine herd by strategical use of serology and culture. In: INTERNATIONAL SYMPOSIUM ON THE EPIDEMIOLOGY AND CONTROL OF SALMONELLA IN PORK, 3., 1999, Washington. Proceedings...Washington, 1999. p.261-263.

PARRY, C.M. Antimicrobial drug resistance in Salmonella enterica. Curr. Op. Inf. Dis., v.16, p.467472, 2003.

PORTARIA $\mathrm{n}^{\circ} 451$ de 19 de setembro de 1997. Padrões microbiológicos para produtos expostos à venda ou de alguma forma destinados ao consumo. Diário Oficial da União, Brasília, 22 de setembro de 1997. Seção I, p.21005-21012.

REIS, R.B.; KRUGER, C.S.; MACIEL, M.S. Salmonella spp. em produtos cárneos comercializados no município de Cuiabá - MT. Avaliação da metodologia de pesquisa. Modelos de resistência a drogas antimicrobianas. Cienc. Tecnol. Alim., v.15, p.74-78, 1995.

ROSTAGNO, M.H. Epidemiologia e diagnóstico das infecções por Salmonella sp. em suínos. 2002. 56f. Tese (Doutorado) - Escola de Veterinária, Universidade Federal de Minas Gerais, Belo Horizonte.

SCHLOSSER, W.; HOGUE, A.; EBEL, E. et al. Analysis of Salmonella serotypes from selected carcasses and raw ground products sampled prior to implementation of the pathogen reduction; Hazard Analysis and Critical Control Point final rule in the US. Int. J. Food Microbiol., v. 58, p. 107-111, 2000.

SCHWARZ, S.; CHASLUS-DANCLA, E. Use of antimicrobials in veterinary medicine and mechanisms of resistance. Vet. Res., v.32, p.201-225, 2001.

SILVA, L.E.; GOTARDI, C.P.; VIZZOTO, J.D. et al. Infecção por Salmonella enterica em suínos criados em um sistema de produção do sul do Brasil. Arq. Bras. Med. Vet. Zootec., v.58, p.455-461, 2006

SOJKA, W. J.; GITTER, M. Salmonellosis in pigs with reference to its public health significance. Vet. Rev. Annot., v.7, p.11-28, 1961. 